\title{
Qualitative Analysis of a Virtual Near-Peer Pediatric Boot Camp Elective
}

\author{
Laura Even Elliott ${ }^{1}\left[\right.$ D John J. Petosa Jr. ${ }^{2}$ Amy B. Guiot ${ }^{3,5} \cdot$ Melissa D. Klein $^{3,4} \cdot$ Lisa E. Herrmann $^{3,5}$
}

Accepted: 4 November 2021 / Published online: 17 January 2022

(c) The Author(s) under exclusive licence to International Association of Medical Science Educators 2021

\begin{abstract}
Objective To explore fourth-year medical students' experience with a virtual, near-peer facilitated pediatric boot camp through the lens of self-determination theory (SDT).

Methods We developed a virtual pediatric boot camp elective for fourth-year medical students pursuing pediatric residency using Kern's six steps of curriculum development. The two-week virtual elective consisted of facilitated video conferences and small group discussions led by two senior pediatric residents. Semi-structured focus groups were conducted after elective completion. Using SDT as our conceptual framework, we explored participants' experience with the near-peer facilitation of the boot camp. Focus group recordings were transcribed and thematically analyzed using deductive coding for SDT, with inductive coding for themes outside the theory's scope. Saturation was reached after three focus groups. The codebook was iteratively revised through peer debriefing between coders and reviewed by other authors. Credibility was established through member checking.

Results Ninety-two percent of eligible medical students $(n=23 / 25)$ participated in the boot camp with attendance ranging from 18-21 students per session. Twelve students (52\%) participated in three focus groups. Qualitative analysis identified five major themes. Four themes consistent with SDT emerged: competence, autonomy, relatedness to near-peers, and relatedness to specialty/institution. The learning environment, including the virtual setting, emerged as an additional, non-SDT-related theme.

Conclusions Medical students' experience with our virtual boot camp closely aligned with SDT. Near-peer relatedness emerged as a unique theme which could be further investigated in other aspects of medical student education. Future research could evaluate higher-level learning outcomes from near-peer educational opportunities.
\end{abstract}

Keywords Near-peer facilitation · Boot camp $\cdot$ Virtual training $\cdot$ Medical student education

Laura Even Elliott

Laura.Even@cchmc.org

1 Division of Emergency Medicine, Cincinnati Children's Hospital Medical Center, 3333 Burnet Ave, MLC 1005, Cincinnati, OH 45229, USA

2 Department of Pediatric Emergency Medicine, Monroe Carell Jr. Children's Hospital at Vanderbilt, 2200 Children's Way, Room / Suite 1025, Nashville, TN 37232, USA

3 Department of Pediatrics, University of Cincinnati College of Medicine, 3230 Eden Ave, Cincinnati, OH 45267, USA

4 Division of General Pediatrics and Community Pediatrics, Cincinnati Children's Hospital Medical Center, 3430 Burnet Ave, MLC 2011, Cincinnati, OH 45229, USA

5 Division of Hospital Medicine, Cincinnati Children's Hospital Medical Center, 3333 Burnet Ave, MLC 9016, Cincinnati, OH 45229, USA

\section{Introduction}

During the COVID-19 pandemic, fourth-year medical students missed vital in-person educational opportunities. Educators filled this need with virtual education, including virtual boot camps [1-3]. Residency preparatory boot camps supplement undergraduate medical learning, demonstrating improvements in skills, knowledge, and confidence [4]. Pediatric boot camp electives have reported outcomes of increased self-assessed confidence in residency-specific tasks and communication skills $[3,5,6]$.

Near-peer facilitation has been implemented in medical student pre-clinical and clinical education. Both learners and teachers have documented benefits including increased test scores [7], increased self-efficacy [8, 9], and improved understanding of material with long-term retention [10]. 
While pediatric boot camps are not novel, there is little evidence on the impact of near-peer facilitation on these courses. The suspension of in-person residency elective rotations during COVID-19 provided the opportunity for residents to serve as near-peer facilitators and afforded medical students a unique educational opportunity to prepare for residency.

Self-determination theory (SDT) purports that intrinsic motivation is mediated through competence, autonomy, and relatedness, which we anticipated would align with student motivation to participate [11]. Within the theory of SDT, external factors, such as learning environment and teaching style, can catalyze or undermine intrinsic motivation [12]. In this study, we explored students' experience with nearpeer facilitation of a virtual pediatric boot camp through the lens of SDT.

\section{Materials and Methods}

\section{Participant Selection}

Fourth-year medical students at the University of Cincinnati College of Medicine (UCCOM) who already matched into a pediatric or combined-pediatric residency program in the 2020 Residency Match were eligible for study participation. Two students who delayed Match to 2021 were also included. We contacted eligible students via email once to assess interest in participation.

\section{Curriculum Development}

We applied Kern's six-step approach to curriculum development to design and implement the boot camp [13]. Interested students and program directors of UCCOM's affiliated pediatric residency completed a targeted needs assessment via electronic survey. The 18-question, Likert-scale student survey asked about confidence in diagnosis and management of common pediatric diseases and residency tasks. The 20-question, Likert-scale program director survey focused on clinical knowledge and skills of a typical incoming intern. Content for the survey was guided by the Council on Medical Student Education in Pediatrics (COMSEP) acting internship (AI) objectives, which were felt to represent competencies that graduating medical students should have in pediatrics. Survey items were primarily derived from the sections on "Patient Care," "Medical Knowledge," and "Interpersonal and Communication Skills" [14]. In addition, the AI elective director served as a local expert on expected competencies of graduating students.
The goal of the curriculum was to improve the confidence of fourth-year medical students' medical management of common pediatric problems and ability to complete frequently encountered residency tasks. Course content, based on the results of the surveys, was created and facilitated by two second-year pediatric residents and reviewed by the AI elective director. The course was conducted via Zoom ${ }^{\mathrm{TM}}$ and consisted of video conferences, small group discussions in break-out rooms, and role modeling by near-peer facilitators. While the AI elective director reviewed content for accuracy prior to sessions, all sessions were facilitated by the two second-year residents, providing exclusively near-peer facilitation. Most sessions were interactive, with participating students addressing knowledge-check questions and/or completing activities in small groups. The course occurred over 2 weeks in May 2020, with two- to three-hour sessions 5 days per week. The course schedule, including topics, is depicted in Table 1. Broadly, the sessions primarily addressed inpatient and outpatient management of common pediatric pathologies (e.g., bronchiolitis, asthma, hyperbilirubinemia), commonly used therapies (e.g., oxygen, antibiotics, intravenous fluids), documentation, and communication with co-residents, patient families, and other providers.

\section{Study Design and Data Collection}

After course completion, students were invited to participate in semi-structured focus groups to explore their experience. We developed a question guide focusing on exploring the impact of near-peer facilitation through the lens of SDT (Supplement). The question guide was reviewed by three physicians with expertise in medical student education and medical education research. Questions were piloted by a resident from an outside residency program for clarity. Focus groups were facilitated by two authors via Zoom ${ }^{\mathrm{TM}}$ [15]. The Institutional Review Board approved this study as exempt.

\section{Data Analysis}

Focus groups were recorded, transcribed, and analyzed by two authors using deductive coding for SDT, with inductive coding for themes outside the theory's scope. The authors discussed codes and resolved discrepancies before further transcript review to create a codebook. The codebook was iteratively revised through peer debriefing 
Table 1 Course content and schedule for the near-peer facilitated pediatric boot camp course

\begin{tabular}{|c|c|c|c|}
\hline Day & Topic & Primary educational method & Small group breakout topic \\
\hline \multirow[t]{4}{*}{1} & Introduction to elective & N/A & \\
\hline & Emergency medicine "quick hits" & Facilitated interactive discussion* & \\
\hline & Child abuse & Facilitated interactive discussion* & \\
\hline & Medication dosing & Didactics & \\
\hline \multirow[t]{4}{*}{2} & Responding to decompensation & Facilitated interactive discussion* & \\
\hline & Making mistakes & Facilitated interactive discussion* & \\
\hline & Disclosing errors & Facilitated interactive discussion* & \\
\hline & Dealing with angry parents & Facilitated interactive discussion* & \\
\hline \multirow[t]{4}{*}{3} & Asthma & Facilitated interactive discussion* & Asthma admission orders \\
\hline & Bronchiolitis & Facilitated interactive discussion* & Bronchiolitis admission orders \\
\hline & Oxygen and ventilators & Facilitated interactive discussion* & \\
\hline & Ear, nose, and throat & Facilitated interactive discussion* & \\
\hline \multirow[t]{3}{*}{4} & Family-centered rounds & Didactics & Presentation practice with non-medical facilitator \\
\hline & Handoffs & Didactics & \\
\hline & Night shift & Didactics & \\
\hline \multirow[t]{4}{*}{5} & Acute gastroenteritis & Facilitated interactive discussion* & \\
\hline & Fluids and electrolytes & Facilitated interactive discussion* & $\begin{array}{l}\text { Determination of appropriate fluids based on clinical } \\
\text { scenario }\end{array}$ \\
\hline & Failure to thrive (FTT) & Facilitated interactive discussion* & Differential diagnosis of FTT \\
\hline & Hyperbilirubinemia & Facilitated interactive discussion* & Differential diagnosis of hyperbilirubinemia \\
\hline \multirow[t]{4}{*}{6} & Skin and soft tissue infections & Facilitated interactive discussion* & \\
\hline & Rashes & Facilitated interactive discussion* & \\
\hline & Joint Pain & Facilitated interactive discussion* & \\
\hline & Antibiotics & Didactics & \\
\hline \multirow[t]{5}{*}{7} & History and Physical notes & Facilitated interactive discussion* & Practice history-taking for various chief complaints \\
\hline & Brief update notes & Didactics & Practice writing brief update notes \\
\hline & Progress notes & Didactics & \\
\hline & Discharge summaries & Didactics & \\
\hline & Communication with primary pediatricians & Didactics & \\
\hline \multirow[t]{4}{*}{8} & Newborn exam & Facilitated interactive discussion* & \\
\hline & Developmental milestones & Didactics & \\
\hline & Vaccines & Didactics & \\
\hline & Adolescents & Didactics & Adolescent social history questions \\
\hline \multirow[t]{3}{*}{9} & Communicating with nurses & Facilitated interactive discussion* & Whole group discussion with labor and delivery nurse \\
\hline & Calling consults & Didactics & \\
\hline & The death exam & Didactics & \\
\hline \multirow[t]{4}{*}{10} & Neonatal fever & Facilitated interactive discussion* & Neonatal fever admission orders \\
\hline & Seizures & Facilitated interactive discussion* & \\
\hline & Interpreting common laboratory tests & Facilitated interactive discussion* & \\
\hline & A day in the life of a resident & Didactics & \\
\hline
\end{tabular}

*Facilitated interactive discussions included short case-based questions and/or knowledge check questions throughout the lecture

between coders and reviewed by the other authors. Focus groups were continued until no new codes emerged, reaching saturation. Initial transcripts were re-reviewed once the codebook was finalized. Main themes were identified and discussed with all authors until consensus was reached. Credibility was established through member checking [15].

\section{Results}

Ninety-two percent of eligible medical students $(n=23 / 25)$ participated in the boot camp, with attendance at each session ranging from 18 to 21 students per session. Twelve boot camp participants (52\%) volunteered to participate in one of three focus groups. 
Table 2 Themes, subthemes, and representative quotes identified during thematic analysis of focus groups conducted following the near-peer facilitated pediatric boot camp course

\begin{tabular}{|c|c|c|}
\hline Theme & Subtheme & Representative quotes \\
\hline \multirow[t]{3}{*}{ Competence } & Decompensation and situational awareness & $\begin{array}{l}\text { "I do think it was more valuable to talk about what you do in the } \\
\text { first } 5 \text { minutes of a code and what you do if you walk past a room } \\
\text { and somebody is having a seizure." } \\
\text { "It was very useful for me to walk through what to do if a patient is } \\
\text { having a seizure in front of you." }\end{array}$ \\
\hline & Communication & $\begin{array}{l}\text { "I think [discussing] how to talk to nurses and deal with conflict } \\
\text { and all of those kinds of things was super helpful." }\end{array}$ \\
\hline & Resident tasks & $\begin{array}{l}\text { "Talking through how to order stuff...especially medicines, that's } \\
\text { something that we haven't really done, ordering medicine, order- } \\
\text { ing stuff like that." } \\
\text { "I also liked that we went into admission criteria and discharge } \\
\text { criteria because...if you didn't have a patient with a certain } \\
\text { diagnosis maybe you aren't thinking all the time about what they } \\
\text { need on admission and discharge." }\end{array}$ \\
\hline \multirow[t]{3}{*}{ Autonomy } & Flexibility with attendance & $\begin{array}{l}\text { "There were some days where I couldn't make it the first week, } \\
\text { and it was fine. I'm bummed that I missed out on certain things, } \\
\text { but it was not a big deal, and I can still get a lot out of the course, } \\
\text { so I liked the flexibility that it offered." }\end{array}$ \\
\hline & Fear/anxiety as a motivator & $\begin{array}{l}\text { "I was going to say 'anxiety'..." (In response to being asked what } \\
\text { motivated them to participate in the course) } \\
\text { "I think a big one for me is just uneasiness about being an intern } \\
\text { and just being scared about it." }\end{array}$ \\
\hline & Returning to a medical mindset & $\begin{array}{l}\text { "With everything going on right now, I feel like I've forgotten } \\
\text { what we have to do to be a doctor...I think especially with the } \\
\text { situation right now, which is hopefully very unique, it was good } \\
\text { to be pulled back into school." } \\
\text { "It would have been really jarring not to have had that refresher... } \\
\text { so I thought it was very valuable to put my brain back in that } \\
\text { mindset, of thinking about children's pathology..." }\end{array}$ \\
\hline \multirow[t]{4}{*}{ Relatedness to near-peers } & Resident-specific knowledge & $\begin{array}{l}\text { "I thought it was super helpful because [residents] actually know } \\
\text { what it's like to be in the middle of the night, putting in admis- } \\
\text { sion orders and triaging all this stuff. Not that attendings haven't } \\
\text { been there and know what to do, but they're a little bit further } \\
\text { removed, so [residents] have really great tips for how to actually } \\
\text { logistically handle all of that." }\end{array}$ \\
\hline & Knowledge perceived as more relevant & $\begin{array}{l}\text { "[Residents] know what we're going to be looking at as interns, } \\
\text { and I feel like attendings are a bit removed from that... not that } \\
\text { they wouldn't know, but [residents] have been living and breath- } \\
\text { ing it every day. You work with interns. You just were interns. It } \\
\text { feels like you're a little bit closer to it." }\end{array}$ \\
\hline & Residents as role models & $\begin{array}{l}\text { "It's also nice to hear from people who were in our same shoes a } \\
\text { couple of years ago and see that you were in the same position } \\
\text { that we are now and then looking at where you are a couple of } \\
\text { years down the line and thinking that could be us in the same } \\
\text { field. It makes it feel a lot more real and more attainable." }\end{array}$ \\
\hline & Perceived as more honest & $\begin{array}{l}\text { "You guys did a really good job of building honest communica- } \\
\text { tion by also telling us, 'Hey, these are things that I did as an } \\
\text { intern, and these are mistakes that I made.' It makes it a lot more } \\
\text { comfortable for us to know that ... we're going to make mistakes, } \\
\text { but it's going to be okay and we're going to learn from them and } \\
\text { be able to teach people who come up after us as well." }\end{array}$ \\
\hline
\end{tabular}


Table 2 (Continued)

\begin{tabular}{|c|c|c|}
\hline Theme & Subtheme & Representative quotes \\
\hline & Perceived as less judgmental & $\begin{array}{l}\text { "I would feel way more comfortable learning and talking about } \\
\text { things with [residents] than I would with an attending. It's much } \\
\text { more comfortable and easier to learn." } \\
\text { "Hearing from someone who's a couple years ahead of us means } \\
\text { that you do have more knowledge and experience than we do, but } \\
\text { at the same time it wasn't intimidating, and we felt that we could } \\
\text { ask questions in a non-judgmental way." }\end{array}$ \\
\hline & Limitations to near-peer instruction & $\begin{array}{l}\text { "Attendings have seen lots more kids because they've been around } \\
\text { longer, so they have more of a variety of experiences." } \\
\text { "One disadvantage is that we're not directly simulating what it's } \\
\text { like to work with attendings... so maybe we would use different, } \\
\text { more professional, more medical language if you were speaking } \\
\text { with an attending..." }\end{array}$ \\
\hline \multirow[t]{2}{*}{ Relatedness to institution/specialty } & Institution/program & $\begin{array}{l}\text { "[The facilitators] are going to be our senior residents next year, so } \\
\text { that definitely makes me feel really connected to my institution." } \\
\text { "I think it got me more excited for residency... it kind of started to } \\
\text { form that teamwork relationship, which is really exciting." }\end{array}$ \\
\hline & Specialty & $\begin{array}{l}\text { "I appreciated your enthusiasm for the field. It was contagious...it } \\
\text { just got me even more excited to start residency." } \\
\text { "I see similarities in [the facilitators'] personalities... and it's not } \\
\text { crazy and scary like other specialties can come off. It makes me } \\
\text { feel like this [specialty] is the right one for me." }\end{array}$ \\
\hline \multirow[t]{5}{*}{$\begin{array}{l}\text { Learning environment and course } \\
\text { structure }\end{array}$} & Efficient & $\begin{array}{l}\text { "The content was delivered very efficiently. There were very clear } \\
\text { learning objectives, and I felt like we were really going through } \\
\text { those, and I was getting stuff out of them." }\end{array}$ \\
\hline & Interactive & $\begin{array}{l}\text { "It was fun and interactive but not in a stressful way. I felt like even } \\
\text { when you called on us, we weren't being put on the spot, and if } \\
\text { we got it wrong, no one was going to laugh at us. That pushed us } \\
\text { to interact with each other and the material a little bit more." }\end{array}$ \\
\hline & Instructor consistency & $\begin{array}{l}\text { "I think it was nice to have just two residents doing the course... } \\
\text { so we had two point people... it wasn't overwhelming, and it } \\
\text { wasn't the same person's voice the whole two weeks. We got to } \\
\text { switch it up a little bit which I thought was nice." }\end{array}$ \\
\hline & Non-physician participants & $\begin{array}{l}\text { "I appreciated... the conversations we had with the people you } \\
\text { brought in. I really liked... how to do family centered rounds } \\
\text { with someone who's not medical...And then with nursing com- } \\
\text { munication, having their perspective and understanding we're all } \\
\text { on the same team...I thought was really great." }\end{array}$ \\
\hline & Virtual environment & $\begin{array}{l}\text { "I know there are obviously advantages to doing things in person, } \\
\text { but I honestly really liked the virtual setting, and I think even } \\
\text { if it wasn't necessary, I might have preferred this over being in } \\
\text { person." }\end{array}$ \\
\hline
\end{tabular}

Thematic analysis of the focus group transcripts identified five major themes, four of which aligned with SDT, with nineteen associated subthemes. Table 2 depicts themes, subthemes, and representative quotes.

\section{Theme 1: Competence: Desire for Competence in Clinical Decision-Making, Communication, and Resident Tasks}

Focus group participants identified competence as a factor in boot camp participation. Subthemes included decompensation and situational awareness, communication, and resident tasks. Participants appreciated "walking through how to go to a room where someone is decompensating or responding to a code." Participants also valued learning about interdisciplinary and patient/ family-physician communication. They desired competence in completing residency skills and tasks such as the technical skills of selecting admission orders and ordering weight-based medications. 


\section{Theme 2: Autonomy: Participation Driven by Anxiety Regarding Transition to Residency and Flexibility in Attendance Policy}

The theme of autonomy explored why students opted into the course and continued to attend. Subthemes included flexibility with attendance, fear/anxiety as a motivator, and returning to a medical mindset. Participants appreciated that the course, which did not have attendance requirements, allowed students to attend based on their own schedule. A common reason for participating in the boot camp was "fear" or "anxiety," specifically related to feeling unprepared for residency.

The subtheme "returning to a medical mindset" was specific to the COVID-19 pandemic. Participants identified lack of structure to their days and missed clinical opportunities as motivators to participate in the course. One student reported that, "getting back into the habit of thinking everyday...was definitely a motivating factor."

\section{Theme 3: Relatedness to Near-Peers: Near-Peer Facilitation and Its Associated Benefits and Challenges on Students' Learning Experience}

We noted two distinct themes pertaining to relatedness: relatedness to near-peers (R-NP) and relatedness to institution/ specialty (R-IS). R-NP addressed how near-peer instruction impacted participants' learning experience. Six subthemes within the R-NP theme included resident-specific knowledge, knowledge perceived as relevant, residents as role models, residents perceived as more honest, residents perceived as less judgmental, and limitations to near-peer instruction.

Participants emphasized many positive aspects of nearpeer instruction, suggesting that residents shared knowledge directly relevant to daily resident duties because they are currently engaging in these activities, whereas attendings may not have completed typical resident tasks in years. One student expressed that information felt more relevant because they "could see myself [as a resident] one day," and near-peers served as role models. Participants felt nearpeer facilitators provided realistic advice based on personal experiences, which contributed to participants perceiving near-peer instructors as honest. Near-peer instructors were viewed as less judgmental than attendings, resulting in participants endorsing greater willingness to respond to facilitators' questions and to ask their own.

Participants acknowledged limitations of near-peer instruction, primarily related to the degree of knowledge and experience of near-peers compared to attendings. Participants reported attendings know "what makes a strong and weak resident" because they have more experience teaching residents. Some noted that they would feel the need to "focus more" had attendings taught the course.

\section{Theme 4: Relatedness to Institution/ Specialty: Near-Peer Facilitation Impacted Students' Connection to the Field of Pediatrics and the Institution}

The R-IS theme explores how near-peer instruction impacted participants' relationships to their future residency program, and to pediatrics as a specialty. Participants who matched at their home institution reported having residents as teachers made them feel more connected to the program. Regarding pediatrics as a specialty, one participant reported that the instructors' personalities "reaffirmed" that pediatrics was right for them.

\section{Theme 5: Learning Environment and Course Structure: Importance of an Interactive, Consistent Learning Environment that Encompassed Non-physician Voices}

The final theme, which was not aligned within the SDT framework, encompassed participant perceptions of the learning environment and course structure. Participants described how the course structure impacted their learning experience. Subthemes included efficient, interactive, instructor consistency, non-physician participants, and virtual environment. Participants reported efficiency in the sessions, which addressed each topic in approximately 30 minutes. They appreciated that instructors asked participants questions "and would wait for someone to respond," which was "key for an interactive learning experience." Participants expressed that two instructors provided the appropriate balance of speaker variety and consistent teaching style. Participants reported that including non-physician speakers for relevant topics made "it more real than if we had to simulate those conversations." The virtual course format necessitated by the COVID-19 pandemic was not felt to hinder learning, with some preferring virtual to in-person instruction.

\section{Discussion}

Our resident-facilitated virtual pediatric boot camp was successfully conducted with consistently high attendance. Focus groups exploring students' experience with the near-peer facilitation and its impact on intrinsic motivation yielded themes that aligned with the main components of SDT, competence, autonomy, and relatedness $[16,17]$. A theme addressing the learning environment was also identified.

Participants sought competence in technical residency skills, and clinical and communication skills, such as identifying and responding to decompensation and interdisciplinary communication. This is consistent with a study of new interns in the United Kingdom who identified 
decision-making and responding to emergencies as areas of low confidence [18]. While boot camps have previously addressed communication topics with trained facilitators, standardized patients, or student role play [5], our boot camp incorporated non-physicians for specific communication topics, which was favored by participants, who described these encounters as more realistic.

In terms of autonomy, anxiety and fear were the most common motivators for initial and continued participation in the course. While such anxiety is expected during the transition to residency, we suspect this was amplified by the temporary cessation of clinical rotations during the COVID19 pandemic $[19,20]$. The resulting lack of daily structure and clinical learning opportunities also served as motivation for participation.

Two distinct categories of relatedness, R-NP and R-IS, emerged. The former is a novel aspect of relatedness in SDT. Participants compared near-peer teaching with faculty-led instruction, expressing that near-peers were more relatable and shared more relevant knowledge. This observation is consistent with studies in which students reported benefiting from the recent experience of near-peers, while faculty teaching may seem too advanced or not applicable [7, 8, 21]. Our participants also perceived near-peers as less judgmental than faculty, which has been reported in other near-peer teaching experiences [8].

Furthermore, participants voiced that near-peer facilitators enhanced their connection to the pediatric specialty, highlighting relatedness traditionally associated with SDT. For participants who matched at their home institution, learning from future colleagues promoted a connection to the institution prior to beginning residency. Near-peer education during medical students' transition from pre-clinical years to clinical rotations has previously demonstrated positive learner feedback [9]. The transition from medical school to residency is similarly a unique opportunity for near-peer instruction because of its potential impact on relatedness to institution and specialty.

While residency preparatory boot camps are not novel, we believe our boot camp is the first in pediatrics to utilize a near-peer teaching model. Other published pediatric boot camps have been developed and facilitated only by attending faculty [3, 22, 23], and a recently published toolkit for developing pediatric boot camps does not mention utilizing nearpeers as facilitators [24]. Given the reported increased level of engagement that resulted from relatedness to near-peers, we believe that near-peer education may be underutilized in pediatric residency preparatory courses.

Though participants generally supported the use of nearpeer facilitators, they noted some limitations, such as the perception that near-peers possess less clinical knowledge than attending physicians. It is unclear if this perception correlates with educational outcomes, as limited studies have looked at higher-level outcomes of near-peer learning. However, one study showed students in a near-peer musculoskeletal curriculum had improved test scores compared to previously published passing rates [21], indicating that near-peer facilitation may be as effective as more traditional, attending-led teaching instruction.

Our study has limitations. We studied a single-specialty preparatory boot camp at one institution, which may limit transferability to other specialties or settings. Selection bias may have impacted our focus group participation, as not all boot camp students participated in focus groups. While the focus group participants appeared engaged in the discussion, the small size of the groups may have caused participants to feel pressure to speak in response to silence. However, larger focus groups were not feasible due to scheduling conflicts. Social acceptability bias may have existed in focus groups because of the relationship between moderators and participants. There is also the potential for recall bias, although focus groups were held 3 days after course completion to minimize this.

\section{Conclusions}

The themes identified in our qualitative study align with the key components of SDT: competence, autonomy, and relatedness. Participants desired competence in clinical decisionmaking, communication, and resident tasks. They described autonomy as a key motivator for participation in the course. Relatedness emerged in two different domains: to nearpeer facilitators and to the institution and specialty. While this course was created to fill an educational gap created by COVID-19, the near-peer relational learning could be translated to other formal medical student education. Future research could explore higher-level learning outcomes from near-peer-facilitation and its application in other educational settings.

Supplementary Information The online version contains supplementary material available at https://doi.org/10.1007/s40670-021-01466-w.

Author Contribution Dr. Elliott contributed to study conception and design, curriculum development and implementation, data collection and analysis, preparation of the initial manuscript draft, and manuscript review.

Dr. Petosa contributed to study conception and design, curriculum development and implementation, data collection and analysis, preparation of the initial manuscript draft, and manuscript review.

Dr. Guiot contributed to study conception and design, curriculum development and implementation, data analysis, and manuscript review.

Dr. Klein contributed to study conception and design, data analysis, and manuscript review.

Dr. Herrmann contributed to study conception and design, data analysis, manuscript review, and project supervision.

All the authors read and approved the final manuscript. 
Availability of Data and Material The data that support the findings of this study are available from the corresponding author, Dr. Elliott, upon reasonable request.

\section{Declarations}

Conflict of Interest The authors declare no competing interests.

\section{References}

1. Chick RC, et al. Using technology to maintain the education of residents during the COVID-19 pandemic. J Surg Educ. 2020;77(4):729-32.

2. Bhashyam AR, Dyer GSM. "Virtual" boot camp: orthopaedic intern education in the time of COVID-19 and beyond. J Am Acad Orthop Surg. 2020;28(17):e735-43.

3. Monday LM, et al. Outcomes of an online virtual boot camp to prepare fourth-year medical students for a successful transition to internship. Cureus. 2020;12(6):p.e8558.

4. Blackmore $\mathrm{C}$, et al. Effects of postgraduate medical education "boot camps" on clinical skills, knowledge, and confidence: a meta-analysis. J Grad Med Educ. 2014;6(4):643-52.

5. Burns R, et al. Pediatric boot camp series: obtaining a consult, discussing difficult news. MedEdPORTAL. 2016;12:10437.

6. Metz J, et al. Pediatric boot camp series: infant with altered mental status and seizure-a case of child abuse. MedEdPORTAL. 2017; 13:10552.

7. Khaw C, Raw L. The outcomes and acceptability of near-peer teaching among medical students in clinical skills. Int $\mathrm{J}$ Med Educ. 2016;7:188-94.

8. de Menezes S, Premnath D. Near-peer education: a novel teaching program. Int J Med Educ. 2016;7:160-7.

9. Knobloch AC, et al. The impact of near-peer teaching on medical students' transition to clerkships. Fam Med. 2018;50(1):58-62.

10. Hall S, et al. The benefits of being a near-peer teacher. Clin Teach. 2018;15(5):403-7.

11. Deci EL, Ryan RM. Self determination theory. In: Van Lange PAM, Kruglanski AW, Higgins ET, editors. Handbook of Theories of Social Psychology. Thousand Oaks, CA: Sage Publications Ltd; 2012. p. 416-36.

12. Ryan RM, Deci EL. intrinsic and extrinsic motivations: classic definitions and new directions. Contemp Educ Psychol. 2000;25(1):54-67.
13. Thomas PA, et al. Curriculum development for medical education : a six-step approach. Third edition. ed. 2016. Baltimore: Johns Hopkins University Press. xii, 300 pages.

14. Konopasek L, Sanguino S, Bostwick S, Hillenbrand K. COMSEP and APPD Pediatric Subinternship Curriculum. 2010. Cited 2020 Available from: https://media.comsep.org/wp-content/ uploads/2019/01/30172802/COMSEP-APPDF.pdf.

15. Hanson JL, Balmer DF, Giardino AP. Qualitative research methods for medical educators. Acad Pediatr. 2011;11(5):375-86.

16. Deci EL, Ryan RM. The "what" and "why" of goal pursuits: human needs and the self-determination of behavior. Psych Inquiry. 2000;11(4):227-68.

17. Ten Cate TJ, Kusurkar RA, Williams GC. How self-determination theory can assist our understanding of the teaching and learning processes in medical education. AMEE guide No. 59. Med Teach. 2011;33(12):961-73.

18. Wall D, Bolshaw A, Carolan J. From undergraduate medical education to pre-registration house officer year: how prepared are students? Med Teach. 2006;28(5):435-9.

19. Prescott JE. Important guidance for medical students on clinical rotations during the coronavirus (COVID-19) outbreak. 2020. Cited 2020 Available from: https://www.aamc.org/news-insights/ press-releases/important-guidance-medical-students-clinicalrotations-during-coronavirus-covid-19-outbreak.

20. Theoret C, Ming X. Our education, our concerns: the impact on medical student education of COVID-19. Med Educ. 2020;54(7):591-2.

21. Schiff A, et al. Results of a near-peer musculoskeletal medicine curriculum for senior medical students interested in orthopedic surgery. J Surg Educ. 2014;71(5):734-7.

22. Burns R, et al. A brief boot camp for 4th-year medical students entering into pediatric and family medicine residencies. Cureus. 2016;8(2):e488.

23. Devon EP, et al. A pediatric preintern boot camp: program development and evaluation informed by a conceptual framework. Acad Pediatr. 2019;19(2):165-9.

24. Hartke A, et al. Building a Boot camp: pediatric residency preparatory course design workshop and tool kit. MedEdPORTAL. 2019; $15: 10860$

Publisher's Note Springer Nature remains neutral with regard to jurisdictional claims in published maps and institutional affiliations. 